\title{
RESEÑA DE LIBRO: San Miguel Arregui, Patricia. (2020). Influencer Marketing. Conecta tu marca con tu público. Lid Editorial, España.
}

\author{
Patricia Vargas Portillo* \\ https://orcid.org/0000-0002-0226-3053
}

\begin{abstract}
Como citar: Vargas Portillo, Patricia. (2021). Reseña de Libro: San Miguel Arregui, Patricia. (2020). Influencer Marketing. Conecta tu marca con tu público. Telos: revista de Estudios Interdisciplinarios en Ciencias Sociales, 23 (1), Venezuela. (Pp. 194-198).

DOI: www.doi.org/10.36390/telos231.15
\end{abstract}

Como acertadamente determina el prólogo de la obra, a cargo de Víctor Conde Director General de la Asociación de Marketing de España-, los consumidores, cada vez en mayor medida, buscan marcas realmente comprometidas con determinados valores, la ética, la sostenibilidad y, en definitiva, la sociedad (en realidad parece aludir a la vigencia de la responsabilidad social corporativa -RSC-). Desde que, a comienzos de 2014, la Asociación de Marketing publicó el código ético de marketing, conviene posicionarse a favor de una publicidad ética y comprometida.

Nótese que, aunque no se señale en la obra, los códigos de conducta son una manifestación de la autorregulación y, a su vez, una manifestación de la RSC antes mencionada. Los anunciantes buscan las mejores estrategias que conecten con el cliente y, en numerosas ocasiones, se apoyan en consumidores reales y cercanos con los que pueda conectar sus destinatarios. Esta puede ser una de las motivaciones por la que los influencers se han incrementado, de forma notable, en los últimos años. Esta publicidad se incrementa, de manera sustancial, en parte gracias al desarrollo tecnológico.

Tanto los medios de comunicación como las distintas actividades de comunicación han puesto de moda un nuevo término: influencer. Ahora bien, la publicación Convince \& Convert relativo al marketing de contenidos y redes sociales- advierte que no debemos confundir audiencia con influencia. El que una persona muy conocida -que pueda ser catalogada de celebrity- tenga un notable número de seguidores en alguno de sus perfiles de redes sociales no significa por sí solo que sea influyente. Las personas que pueden ser reputadas influyentes informan sobre un bien y/o servicio, pero también fomentan la participación. En los últimos años se han acuñado un amplio elenco de vocablos que podrían parecer similares: influencer; blogger, Brand Ambassadors -Embajadores de una marca- y los fieles defensores de la marca -Brand Advocates-, se distinguen por el poder de influencia que representan.

La realidad cotidiana pone de manifiesto la gran proyección de futuro que ostenta el marketing de influencers. Tal y como manifiesta el II Estudio con Influencers de SocialPubli (por

\footnotetext{
Doctora en Ciencias Económicas y Empresariales. ESIC Business \& Marketing School. Correo electrónico: jennypatricia.vargas@esic.edu
} 
el que se encuestaron 170 anunciantes y agencias de publicidad de 16 Estados diferentes) casi el $75 \%$ de los anunciantes ha recurrido, en alguna ocasión, a influencers en la publicidad. Asimismo, un $90 \%$ de las marcas y agencias consideran que el sector es muy efectivo. Llama la atención que más del $80 \%$ de los anunciantes mantienen el deseo de incrementar las promociones comerciales en los que intervengan influencers. En virtud de estos últimos, se logra una publicidad que podría calificarse de más natural.

Además, tienen un público más segmentado y dan lugar a un elevado engagement compromiso-. Parece que las tendencias están cambiando dado que los influencers ya no sólo venden productos a través de sus blog o vídeos de YouTube, sino que lo hacen en los directos que realizan. Para las redes sociales y el comercio electrónico, los canales de compra personal podrían relacionarse con el hecho de ir de compras con una persona cercana que escucha sugerencias de qué comprar y que no.

Son muy sugerentes las apreciaciones que, a este respecto, formula Jaume Vicent de TreceBits.com, en su publicación "Los influencers prefieren vender productos en los Directos", en relación a esta materia. Instagram, por ejemplo, cuenta con el instrumento denominando Live Shopping con el que se permite a los creadores de contenidos vender determinados productos en las retransmisiones a través de la red social. Según tal tendencia, Amazon, también en Estados Unidos, lanzó Amazon Live for influencers. El gigante tecnológico (Amazon) pone a disposición de los creadores de contenidos varias herramientas como un chat a tiempo real, más y mejores comisiones, eventos en Amazon Live y otros aspectos.

La autora de la obra es Patricia SanMiguel, Licenciada en Publicidad y Relaciones Públicas por la Universidad Complutense de Madrid y Doctora por la Universidad de Navarra. Es académica en ISEM Fashion Business School y la Universidad de Navarra. Respecto a sus líneas de investigación podemos destacar: el liderazgo de opinión e influencia entre personas; y el análisis del comportamiento del consumidor. Es, asimismo, directora del Observatorio de análisis del impacto digital de las marcas de moda Digital Fashion Brands.

Respecto a la sistemática, se integra por nueve capítulos independientes, así como una introducción y un completo glosario. Seguidamente, nos referiremos, de manera somera, a cada uno de ellos, haciendo las precisiones oportunas en cada caso.

San Miguel se hace eco de las consideraciones que, respecto a esta cuestión, efectúan los periódicos más relevantes a nivel global. Así, por ejemplo, The Guardian señalaba que "las millenials influencers son las nuevas estrellas de la publicidad online".

En 1955, dos sociólogos publicaron una sugerente monografía con el título "Personal Influence", en la que ponían de relieve la existencia de líderes de opinión en distintos ámbitos (política; comercio; moda; y cine). Una de sus grandes aportaciones, como bien destaca San Miguel, estriba en diferenciar entre, por un lado, el liderazgo de opinión oficial, el de los políticos, deportistas de élite y, por otro lado, el liderazgo no oficial o cotidiano. Tales investigadores acuñaron el término influentials para referirse a quienes tienen un liderazgo invisible e inconsciente de persona a persona.

La era de la influencia, a modo de introducción, nos posiciona contextualmente en cómo se desarrolla el fenómeno que estamos analizando. En este sentido, cabe precisar como la tecnología está cambiando todos los ámbitos sociales desde la manera en que trabajamos y nos relacionamos hasta la que compramos o entretenemos. Como anticipa la autora, el influencer marketing está en permanente evolución. La creciente tendencia de los 
RESEÑA DE LIBRO: San Miguel Arregui, Patricia. (2020). Influencer Marketing. Conecta tu marca con tu público.

microinfluencers obedece a que cada día más clientes reclaman la presencia de consumidores expertos que se parezcan más a ellos mismos que a las celebridades. No estamos ante una moda pasajera, sino que durante los próximos años es bastante probable que se aumente la inversión en los mismos.

El segundo capítulo, que versa sobre cómo conectar con los millennials y la generación $Z$... sin olvidarse de la generación X, estudia los caracteres más relevantes de cada generación, sus patrones de consumo y los usos de Internet y de las redes sociales. Se examina cómo interactúan con los influencers y las mejores tácticas para poder conectar con cada generación. Además, se ponen de relieve los motivos y de qué manera se comparten los contenidos en redes sociales, así como los procesos que nos llevan a seguir a otros consumidores. Finalmente, se refiere a los instantes clave para conectar con el consumidor final e influir en sus decisiones. Merced al uso notable de las redes sociales, el influencer marketing ha tenido un mayor impacto en la generación millennial.

Los procesos de influencia y tipologías de influencers, se abordan en el capitulo siguiente. Cuando se analiza quién influye al público y a los clientes, hay distintos tipos de actores influyentes: medios de comunicación; marcas; celebrities; influencers; influentials -que serían los familiares y amigos-. Debe advertirse que los influencers no están de manera estática en una sola categoría. Con el transcurso del tiempo, cambia su rol, su comunidad de seguidores y, con todo ello, su tipología. Las redes sociales hacen posible que se produzca un incremento de personas con influencia no oficial que pasan a tener reconocimiento mundial en el mundo físico y digital. Cada vez más influentials han pasado a ser influencers, llegando a ser reconocidas celebrities.

A la hora de elegir al mejor influencer, deberían tenerse en consideración tres aspectos: qué capacidad tiene para movilizar las opiniones y producir reacciones; la audiencia potencial que puede llegar a tener sobre determinada temática; nivel de compromiso en las conversaciones que se planteen. En cualquier caso, no todos los perfiles encajan con las marcas, la filosofía empresarial y determinados valores. Por ello, resulta necesario realizar un barrido para elegir el mejor perfil acorde a los valores y a los objetivos. La comunicación de las marcas ha de ostentar una base muy arraigada en su propósito, plasmando sus valores en acciones que lo manifiesten, destacando el hacer por delante del decir. Una vez que se ha elegido al influencer, procede comunicar lo que la marca podría aportarles y de qué forma podrán ellos ayudar a la marca. Con transparencia se puede generar una relación de ganancia mutua entre ambas partes que, sin duda, redundará, de forma favorable, en el éxito de la promoción.

Las categorías de influencers, se analizan en el capítulo cuarto, si bien, como advierte la autora, resulta difícil encasillarlos en una sola. Existe un buen número de influencers que, aunque se focalizan en una determinada categoría, a medida que sus comunidades y sus redes sociales aumentan, publican contenido más diverso -sobre todo si los temas tienen relación entre sí-.

El capítulo quinto resulta extraordinariamente sugerente, pues detalla cómo debe procederse para crear un plan de influencer marketing. Plantea una guía con diez pasos que van desde el conocimiento de la marca, sus valores y esencia hasta la medición final de los resultados de la campaña con KPI. El éxito de la campaña dependerá, como señala la autora, de la manera en que se recorra tal camino. 
Una vez analizado cómo se debe efectuar un plan relativo al influencer marketing, el capítulo sexto se refiere a las estrategias que deben utilizarse cuando se trabaje con influencers. Debemos tener muy presentes los objetivos y metas a alcanzar respecto a los objetivos. En este sentido, en primer término, primero deben identificarse las diferencias que concurren entre las acciones de influencer marketing que se realizan de manera orgánica y aquellas que implican un acuerdo pecuniario con el influencer. Como acertadamente indica la obra que se reseña, cuando se trabaja con influencers, resulta relevante qué tipología de relaciones queremos establecer: a corto, medio o largo plazo.

La importante magnitud que está protagonizando el marketing influencer determina que el fenómeno esté englobando cada vez más ámbitos lo que nos permite desarrollar múltiples estrategias tanto en las redes sociales como en el mundo físico. El marketing con influencers, tal y como se establece en el capítulo séptimo, ha dejado de ser una moda pasajera, siendo cada vez más numerosos los patrocinios y el presupuesto que se dedica a estas prácticas.

Esta modalidad de planes de marketing, además de tiempo y recursos económicos, requiere de conocimientos profesionales. A tal fin, han surgido distintas soluciones empresariales para facilitar planes de influencers marketing para las marcas. Dentro de estas últimas, podemos, entre otras, citar las siguientes: plataformas y marketplaces de influencers; agencias especializadas; estudios y talent networks 0 redes de talento; representantes; y herramientas. Todas ellas son analizadas, de manera independiente, por parte de la autora.

El capítulo octavo expone cuatro casos de estudio y algunos supuestos paradigmáticos de acciones que dieron lugar a crisis de reputación. Los casos que se examinan versan sobre empresas muy distintas y de distintas tipologías y múltiples estrategias de influencer marketing. Dentro de la diversidad de supuestos se encuentran empresas consolidadas, emprendedoras, acciones con celebrities y microinfluencers.

Las previsiones de futuro del fenómeno se tratan en el último capítulo de la obra. En efecto, el capítulo noveno alude a la llegada del influencer 3.0 y con ello a las próximas tendencias que se producirán. Resultan especialmente sugerentes las apreciaciones que se formulan respecto a los fake influencers y fake followers. El incremento de la demanda de influencers para participar en campañas de comunicación y marketing ha despertado el anhelo de muchos jóvenes de llegar a ser influencers. Asimismo, numerosas empresas han potenciado la creación de influencers para lograr beneficios pecuniarios. También cabe considerar que se han creado numerosos perfiles de influencers y seguidores mediante bots -que imitan comportamientos humanos.

Por consiguiente, existen influencers con miles de seguidores que en su inmensa mayoría son bots, es decir falsos. En este ámbito, como no podía ser de otra manera, la autorregulación desempeña una labor complementaria. En este sentido, la Word of Mouth Marketing Association -WOMMA-, en su guía relative al influencer marketing, pone de manifiesto que el éxito de las campañas dependerá del ambiente de transparencia y confianza que impere. WOMMA propone seis principios éticos que tanto empresas como influencers deberían observar: confianza; integridad; respeto; honestidad; responsabilidad; y privacidad.

En definitiva, la obra que hemos reseñado representa una sugerente monografía sobre el fenómeno del influencer marketing. Asimismo, cabe advertir que es de lectura fácil, pero contenido riguroso, presentando todos los aspectos de interés para cualquier empresa que 
RESEÑA DE LIBRO: San Miguel Arregui, Patricia. (2020). Influencer Marketing. Conecta tu marca con tu público.

desee iniciarse en esta modalidad publicitaria. No estamos ante una tendencia, sino ante una forma de concebir el reto para la comunicación en el cambio social que estamos protagonizando.

PATRICIA SANMIGUEL

\section{$8235 \quad 8126 \mathrm{~K}$}

Influencer

Marketing

CONECTA TU MAROA

CON TU PÜBLICO 